\title{
Evolving the SP-100 Reactor in Order to Boost Large Payloads to GEO and to Low Lunar Orbit via Nuclear-Electric Propulsion
}

Robert E. English

Lewis Research Center

Cleveland, Ohio

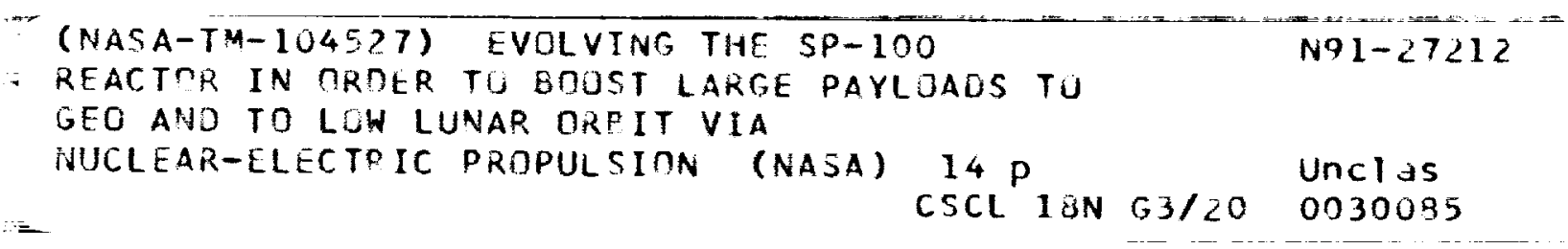

Prepared for the Conference on Advanced Space Exploration Initiative Technologies cosponsored by the AIAA, NASA, and OAI Cleveland, Ohio, September 4-6, 1991

\section{N/Sก}


$-\cdots+\cdots+\cdots+\cdots$ 


\title{
EVOLVING THE SP-100 REACTOR IN ORDER TO BOOST LARGE PAYLOADS TO GEO AND TO LOW LUNAR ORBIT VIA NUCLEAR-ELECTRIC PROPULSION
}

\author{
Robert E. English* \\ National Aeronautics and Space Administration \\ Lewis Research Center \\ Cleveland, Ohio $\mathbf{4 4 1 3 5}$
}

\begin{abstract}
As NASA contemplates sending personnel on long-term missions to the Moon and to Mars, we technologists and mission planners are responsible for delineating the costs and risks involved and for formulating program plans reducing these costs and risks. In our striving to reduce costs and risks, a crucial aspect of those plans is program continuity, that is, the continuing application of a given technology over a long period so that experience will accumulate from extended testing here on Earth and from a diversity of applications in space.

We need to form an integrated view of the missions SEI will carry out, near-term as well as far, and of the ways in which these missions can mutually support one another. Near-term programs should be so constituted as to provide for the long-term missions both the enabling technologies and the accumulation of experience they need. In achieving this, missions in Earth orbit should both evolve and demonstrate the technologies crucial to long-term missions on the lunar surface, and the program for the lunar laboratories should evolve and demonstrate the enabling technologies for exploration of the surface of Mars and for flights of human beings to Mars and return.

In the near term, the program for the Space Station should be directed and funded to develop and demonstrate the solarBrayton powerplant that will be most useful as the power generator for the SP- 100 nuclear reactor.
\end{abstract}

\section{Introduction}

In response to the President's request, NASA has begun examining ways in which we would first establish permanent

* Distinguished Research Associate. operational bases and astrononical laboratories on the lunar surface and would then transport an inhabited spacecraft to Mars and return. Both the financial costs and the financial risks of carrying out these ventures loom large.

New technologies are frequently cited as the means for reducing both these costs and risks of mission execution, but the new technologies themselves introduce additional costs and risks. How do we balance those costs and risks? How do we exploit advancing technologies in order to reduce both program costs and risks to personnel while simultaneously limiting the costs and risks of the advancing technologies themselves? I will strive to address that important issue, the approach representing my view alone and not necessarily that of the Lewis Research Center.

In large part, I propose that we take a broad, overall view of the entire SEI program. In shaping that program, we should choose each new technology or capability for its contribution to the entire program, pruning from the program those elements of limited utility.

For example, we should not return to the Moon for a brief daytime visit; we already did that in the Apollo program, with only minimal contribution to future long-term stays on the lurar surface. Now we look toward permanent laboratories and bases on the lunar surface, so we should get under way those enabling programs that will lead to the new capabilities required, that is, the capabilities for continuous residence on the Moon. In choosing concepts for, say, power generation or propulsion, we should display similar vision and judgment. The concepts we select, develop, and employ should themselves have breadths of application extending from LEO to low lunar orbit (LLO), to the surfaces of the Moon and Mars, and to transportation to Mars and return.

During merely daytime visits to the Moon, for example, we could rely on arrays of solar photovoltaic cells as our principal power source. But because merely daytime visits are deadend missions, I recommend against that approach. For con- 
tinuing operation of any significant base or laboratory throughout the lunar night which lasts almost 15 Earth-days, nuclear power is a sine qua non. Thus, my recommendation is to leapfrog solar power on the Moon and instead to start on the path for which each step is constructive because it will carry us closer to our goal of long-term use of the lunar surface, and that, in my mind, requires nuclear power.

Several reasons are crucial in my recommending this approach: If we avoid a multiplicity of approaches, we will save both time and money. No one will argue with my claim that developnent of such a solar powerplant would consume both time and money, and that a mission for merely daytime visits would itself consume more of both. Thus, we will all agree that skipping the photovoltaic powerplant and the daytime visits would save us both time and money. But I believe that the risks to the personnel involved will also decrease if we forgo the photovoltaic approach. If, for a given total expenditure, we focus our efforts on the necessary nuclear powerplant, that powerplant will be more highly developed and thus more reliable and enduring than it otherwise would.

Beyond the Moon, we also have the same responsibility for planning missions to Mars. We must plan the lunar missions so as to create, to rely on, to exploit, and to validate the very concepts that we will need for our flights to Mars, just as we must require of the Space Station the demonstration and exploitation of the subsystems, such as the powerplant, needed on the Moon.

By taking a unified view of our current and future missions and, through that, by building on a successful past in order to guarantee our future, we ought to be able to reduce the risks and the costs of these future missions. We will also likely save a few lives in the process. And, if we wisely choose the technologies we support, we will still be able to realize performances close to the best achievable. My approach to this paper is to accept the responsibility for delineating just such a programmatic path for power generation for the SEI missions.

In my view, the keys to successful exploitation of the new teclnologies are the following:

(1) After assessing the potential of a concept for improved performance and wide application, introduce margins in design in order to reduce programmatic risks. This should reduce the time, the money, and the risks for successful development.

(2) Exploit the concept in a variety of applications, showing through actual service in space the concept's performance, durability, and reliability.

(3) During a period of successful utilization in space, evolve the concept toward its performance potential through successive reduction of the design margins introduced at the programıs start.
In addition, we might be wise enough to choose a technological path that, although extending from a modest beginning to a grand and glorious future, does so in a succession of modest steps, each of modest risk and cost. Such an achievement requires formulation of a total program that is, to some degree, monolithic and conceived with vision. I will try to outline just such an approach. Opposed to such an integrated program emphasizing durability, reliability and cost is a succession of designs, one promising a 10-percent mass reduction at this power level and a second promising a 10 . percent reduction at another power level. Some steadfastness in evolving a given class of powerplant to higher powers and to higher performance can not only save us an enormous amount of money but can also reduce both the programmatic risks and the risks to the people involved. Delineation of just such an integrated approach is my principal goal.

The only space nuclear powerplant under active development is SP-100, this development requiring about 20 years from program initiation in 1982 and the expenditure of perhaps $\$ 1$ to 5 billion. For this very reason, responsible program planning would utilize this powerplant and its near-term derivatives rather than start over with an entirely new approach.

\section{The Missions}

In what follows, missions leading to continuous residence on the lunar surface will be emphasized. Because my study of missions to Mars is still rudimentary, the potential benefits to the Martian missions themselves are merely inferred and stated in general terms.

On the other hand, it is already clear that continuous support of operational bases on the lunar surface depends upon economical transportation of supplies and equipment to the Moon. Within the context of this paper, crucial issues are how such power and propulsion capabilities might be evolved in a succession of modest steps, this evolution reducing not only the cost and risk in system development but ultimately also the risk to the mission and to the personnel involved. In emphasizing this low-risk, incremental evolution of future capabilities, I suggest early reliance on nuclear-electric propulsion (NEP) for payload-boosting from low Earth orbit (LEO) to geosynchronous Earth orbit (GEO) as a valuable precursor of both transport of cargo to low lunar orbit (LLO) and of continuous occupation of laboratories on the lunar surface.

Even for transport of cargo to either GEO or LLO via NEP, the time of transport is an important measure of merit, along with the mass of the payload itself. Both time of transport and payload mass will therefore receive equal enphasis herein.

Two modes of transport of cargo are evident: one-way trips and roundtrips. Both will be considered. 


\section{SP-100}

In this nuclear powerplant, the nuclear reactor produces $2500 \mathrm{~kW}$ of heat $(\mathrm{kWt})$ and thereby heats a pumped stream of molten lithium to $1350 \mathrm{~K}$, the lithium transporting its sensible heat to a power-generating system. Salient features of this class of reactor are that it is compact because of its lithium coolant and that it is suitable for use with any power generator that can utilize the stream of molten lithium at $1350 \mathrm{~K}$. In the SP-100 powerplant concept, the lithium sustains a thermoelectric power generator and maintains a hot-junction temperature of $1300 \mathrm{~K}$. The studies of alternative power generators have chiefly focused on the turbogenerating Brayton cycles' and the reciprocating Stirling engines, ${ }^{2}$ but other possible concepts would use potassium-vapor Rankine cycles ${ }^{3}$ or AMTEC (alkali-metal thermoelectric energy converter). ${ }^{4}$ A virtue of the SP- 100 approach is the suitability of the reactor for use with a variety of power generators, a significant programmatic advantage over thermionic reactors. ${ }^{5}$

For the SP- 100 nuclear powerplant, overall efficiency of its thermoelectric power generator is 0.04 , so the rated power produced from the reactor's $2500 \mathrm{kWt}$ is $100 \mathrm{kWe}$. A representative mass breakdown of the powerplant from a design review in May 1988 is as follows: ${ }^{6}$

\begin{tabular}{|l|r|}
\hline \multicolumn{1}{|c|}{ Component } & $\begin{array}{c}\text { Mass, } \\
\mathrm{kg}\end{array}$ \\
\hline Reactor & 803 \\
Shield & 1255 \\
Primary heat transport & 632 \\
Reactor's instruments and control & 359 \\
Power generation & 409 \\
Heat rejection & 1027 \\
PMAD & 399 \\
MechanicaV/structure & 538 \\
& \\
Total mass, kg & 5422 \\
\hline
\end{tabular}

The corresponding specific mass of this $100-\mathrm{kWe}$ powerplant is thus $54.22 \mathrm{~kg} / \mathrm{kWe}$. The first four components in this list (totalling $3049 \mathrm{~kg}$ ) comprise the nuclear heat source, and the lasst four components (totalling $2373 \mathrm{~kg}$ ) are associated with the thermoelectric power-generating system.

The estimates of total mass for the SP- 100 powerplant have risen and fallen over the intervening period, ranging from 4460 to $5531 \mathrm{~kg} .^{7}$ At the same time, the predicted mass of the nuclear heat source has also risen and fallen from $3049 \mathrm{~kg}$, ranging from 2468 to $3131 \mathrm{~kg}$. The final masses of the powerplant and of its nuclear heat source must thus be treated as a bit uncertain at this time.

In my analysis that follows, I will use the $3049 \mathrm{~kg}$ listed above for the mass of SP-100's nuclear heat source and $5422 \mathrm{~kg}$ for the complete powerplant, but we should keep in mind that these masses might finally turn out to be as much as 18 or 19 percent less than these values. In turn, in assessing competitive power-generating systems for use with this reac- tor, I will use the same 3049-kg nuclear-heat-source mass with all of them.

For SP-100's thermoelectric power generator, specified output is $200 \mathrm{VDC}$ and $500 \mathrm{~A}$, a voltage technologically difficult even at this low value. For a voltage output that low, considerable additional power conditioning is necessary in order for this power to be used for electric propulsion. A previous JPL study reflects the severity of the problem. In reference 8 , power conditioning added 31.5 percent to powerplant mass and decreased net output by 22.7 percent, the conbined effect being a 70 percent increase in specific mass. For NEP, thruster mass must, of course, also be included. For the combined mass of thrusters and their power conditioning for use with SP-100, I optimistically added only $5 \mathrm{~kg} / \mathrm{kWe}(500 \mathrm{~kg}$ altogether) to the specific mass of the SP-100 powerplant, the total then being $59.22 \mathrm{~kg} / \mathrm{kWe}$.

Because this near-term nuclear powerplant will most likely be used in near-term applications, I focussed my attention on its use in the near-term mission of boosting payloads on oneway trips from LEO to GEO. In order to shift the orbit plane by the $28.5^{\circ}$ required by launching from Cape Canaveral, the thrust vector was slued as a function of azimuth angle during the ascent from LEO to GEO, the corresponding penalty in delta- $V$ being taken into account. For each given time for transit from LEO to GEO, the value of specific impulse was chosen to maximize the payload delivered to GEO. As shown by Fig. 1, 8-tons of net payload can be boosted to GEO in 180 days. Inasmuch as SP-100 would also be delivered to GEO, some fraction of its mass (corresponding to the fraction of its $100 \mathrm{kWe}$ useful to the payload) could be added to this net payload.

Larger payloads are possible but only if longer transit times are accepted. For example, net payload can be increased to 16 tons if a transit time of a year is acceptable. For transit times ranging from 180 to 365 days, optimum specific impulse varies from 2500 to $4000 \mathrm{sec}$.

\section{Brayton $+2500-\mathrm{kWt}$ Reactor}

Inasmuch as the mass of SP-100's nuclear heat source is $3049 \mathrm{~kg}$, specific mass of that $100-\mathrm{kWe}$ powerplant must exceed $30 \mathrm{~kg} / \mathrm{kWe}$ even if the thermoelectric power generator had no mass at all. In exploiting this reactor and its large investment of time and money, the key to reduced specific mass is, of course, to increase the efficiency of power generation. With its overall efficiency of the order of 0.3 for power generation, Brayton offers the potential to produce about $700 \mathrm{kWe}$ from this same nuclear heat source and thereby to markedly cut specific mass. In addition, each kilowatt of output is valuable in its own right, and a $700-\mathrm{kWe}$ powerplant will obviously produce seven times the beneficial product of a 100-kWe powerplant. Development of the SP- 100 reactor is such a costly, time-consuming enterprise that we should strive to get from this reactor just as much electric power as we possibly can. With its potential for high efficiency already 
established, the Brayton cycle looks like a good candidate to achieve all these benefits.

An additional question is how we might reduce the risk of the SP-100 program. Most important is the range of operating temperatures. Currently, the reactor is planned to produce a mean reactor-outlet temperature of $1350 \mathrm{~K}$, consonant with the thermoelectric hot-junction temperature of $1300 \mathrm{~K}$. I will examine reducing reactor-outlet temperature by $150 \mathrm{~K}$, that is, to $1200 \mathrm{~K}$. Correspondingly, turbine-inlet temperature for the Brayton cycle is limited to $1150 \mathrm{~K}$.

\section{0-K Brayton}

Reference $\mathrm{I}$ is my point of departure for assessing Brayton power generation, a design study of $400-\mathrm{kWe}$ nuclearBrayton powerplants based on nuclear heat sources supplied by Los Alamos National Laboratory; inasmuch as these nuclear heat sources had substantially lower mass than cited above for SP-100, I will instead use the $3049 \mathrm{~kg}$ for the nuclear heat source of SP-100, just as for thermoelectric power generation above.

In directing this contracted study, ${ }^{1}$ JPL specified to their contractor that the Brayton components be designed for $120000 \mathrm{hr}$ of operation at full power, roughly 14 years and about double the life JPL requires of competing thermoelectric powerplants. In addition, JPL specified 100 percent redundancy in power generation, an approach that to me seems extravagant in its mass addition. Instead, I assume modular construction of the power-generating system and a mission strategy that accepts some loss of power. (The manner in which such failures might be accepted will be discussed below.) Masses of the heat exchangers are scaled from those in Ref. 1 in direct proportion to the rate at which heat is being transferred and in inverse proportion to the temperature drop across the heat exchangers. The specific masses of the rotating components were those in Ref. 1 , and mass of the waste-heat radiator was taken as $6 \mathrm{~kg} / \mathrm{m}^{2}$, a representative value.

For a fixed heat input of $2500 \mathrm{kWt}$ and the constant turbineinlet temperature of $1150 \mathrm{~K}$, the attainable ranges of power and specific mass are shown by Fig. 2. Each point plotted is a possible design point and represents a selected combination of design variables, chiefly compressor pressure ratio and compressor-inlet temperature. Generally, the most suitable range of powerplant design is the envelope of the points plotted. In the absence of a specified power demand, my attention focusses first on the minimum specific mass. Next I contemplate points to the right of this minimum, trading off specific mass in order to obtain still higher powers.

In preparing this plot, I considered a range of recuperator effectiveness, the value chosen for Fig. 2 (0.90) being that yielding near the minimum powerplant mass at a selected power level of $700 \mathrm{kWe}$. Increasing recuperator effectiveness, while adding to recuperator mass, decreases the heat to be rejected and thereby the radiator mass as well. As is usually the case, there's a tradeoff between recuperator mass and radiator mass.

Specific mass for the powerplant reaches a minimum at about $660 \mathrm{kWe}$; somewhat higher powers are achievable at the expense of modest increases in specific mass. For specificity, let's focus on $700 \mathrm{kWe}$ at $17 \mathrm{~kg} / \mathrm{kWe}$. Despite the $150-\mathrm{K}$ reduction in reactor-outlet temperature below the design value for SP-100, substitution of Brayton power generation for thermoelectric raises useful power from 100 to $700 \mathrm{kWe}$, overall efficiency rises from 0.04 to 0.28 , and powerplant specific mass decreases from 54 to $17 \mathrm{~kg} / \mathrm{kWe}$.

For use of this powerplant in electric propulsion, the mass of the thrusters and their power conditioning must, of course, be added to the mass of the powerplant. In a dynamic power system such as this, existing technology for the synchronous alternators to produce the power will permit generation at a voltage matching that needed by the principal load of the ion thrusters. In that event, only rectification and filtering would be needed for that principal load. Voltage transformation would still be needed for the secondary loads, but because of the high voltages available, even this power conditioning would be efficient and of low mass. For these reasons, the combined specific mass of the thrusters and their power conditioning was taken as $2 \mathrm{~kg} / \mathrm{kWe}$, notwithstanding that a specific mass this low has not yet been demonstrated for the complete thrust subsystem. In turn, the total specific mass of powerplant, power conditioning, and thrusters was $19 \mathrm{~kg} / \mathrm{kWe}$.

This 700-kWe powerplant was then considered for hauling cargo from LEO to GEO in one-way trips (Fig. 3), just as for SP-100 (Fig. 1). In 180 days, 63 tons of net payload could be delivered to GEO, roughly 8 times what SP-100 can deliver in that same time. Alternatively, 39 tons could be delivered in 100 days, performance beyond the capacity of SP- 100 . Besides these payloads, the 700-kWe powerplant would also be boosted to GEO, so some fraction of its power output and its mass might be useful additions to these payloads. For the range of Fig. 3, the optimum values of specific impulse range from 2600 to 5400 sec.

The essential point to be drawn from this comparison of high-temperature thermoelectric $(1300 \mathrm{~K})$ and lowtemperature Brayton $(1150 \mathrm{~K})$ power generation is that very large performance gains are achievable in a program of lower risk and thereby most likely of lower cost. The reduction in reactor-outlet temperature from 1350 to $1200 \mathrm{~K}$ would reduce the risk in operating the reactor successfully and thus likely permit the reactor to be brought into useful service in a briefer time and at lower cost. Production of $700 \mathrm{kWe}$ by a Brayton powerplant from $2500 \mathrm{kWt}$ of heat requires powerplant efficiency of 0.28 . Efficiency of 0.29 has already been demonstrated at the more-difficult level of $10 \mathrm{kWe}$ and coupled with $38057 \mathrm{hr}$ of endurance testing, all with turbine-inlet temperature of $1150 \mathrm{~K}$ (Ref. 9, p. 13). Further development and demonstration of the components of that powerplant improved their individual performances, from which we calculate that efficiency of the Brayton power generator should then rise 
from 0.29 to 0.32 through use of these improved components. The technology for Brayton performance superior to this prediction has thus already been demonstrated in the laboratory. All these factors contribute to substantial reductions in risk for the low-temperature Brayton power generator and for the SP100 reactor at the reduced reactor-outlet temperature.

That $150-\mathrm{K}$ reduction in reactor-outlet temperature could be treated as pure margin in the reactor-Brayton program, pernitting early benefits from its early completion. If the reactor has, in fact, the capacity to operate at its design level of $1350 \mathrm{~K}$, operation at the higher temperature need not be forgone. After a period of successful operation at $1200 \mathrm{~K}$ as I propose for, say, $10000 \mathrm{hr}$, reactor-outlet temperature might be successively raised to $1300 \mathrm{~K}$ and then to the full $1350 \mathrm{~K}$, operation in each case continuing for another $10000 \mathrm{hr}$. This evolutionary approach that I advocate reduces the costs, the risks, and the time in bringing a new technology into useful application without sacrificing, over the long term, any of the performance of which the concept is capable.

Correspondingly, the peak cycle temperature of the Brayton power generator would simultaneously be raised to $1300 \mathrm{~K}$, so let's next consider how that might be achieved.

1300-K Brayton- In principle, turbine-inlet temperature could be raised to $1300 \mathrm{~K}$ through use of the same refractory alloy (PWC-11) as for thermoelectric power generation. Alternatively, ASTAR-811C could be used in providing a large margin of temperature tolerance (See discussion of ASTAR-811C below.).

The powerplant performance that results is shown by Fig. 4 through use of the SP-100 nuclear heat source at its full potential of $1350-\mathrm{K}$ reactor-outlet temperature. Specific mass reaches its minimum of about $13 \mathrm{~kg} / \mathrm{kWe}$ at $750 \mathrm{kWe}$. In my choice of 0.92 for recuperator effectiveness, I opted for increasing power output to $850 \mathrm{kWe}$; at this power level, the effectiveness of 0.92 produces the minimum specific mass of $13.6 \mathrm{~kg} / \mathrm{kWe}$, and overall powerplant efficiency is then 0.34 . By increasing operating temperatures, we gain in both power output and specific mass; the 850-kWe output is a 750-percent increase over that from the thermoelectric power generator, and specific mass is decreased by 75 percent.

For boosting payloads to GEO, an NEP truck exploiting this Brayton powerplant could operate on either one-way or roundtrips. Inasmuch as one-way trips were shown in Fig. 3, roundtrips are shown in Fig. 5. The total specific mass of $15.6 \mathrm{~kg} / \mathrm{kWe}$ includes $2 \mathrm{~kg} / \mathrm{kWe}$ for power processing and ion thrusters, as before. The payloads deliverable to GEO range from 14 to 18 tons for transit times ranging from 50 to 200 days. Optimum specific impulse for these missions ranges from 3000 to $15000 \mathrm{sec}$.

In 100 days, 16.8 tons of payload can be boosted to GEO, less than half of what can be delivered on one-way trips (Fig. 3). The anticipated benefit offsetting this reduction in payload per trip is that the NEP truck would be fully reusable and thus would continue to shuttle between LEO and GEO, making many roundtrips. If the roundtrips were spaced just
6 months apart and continued for 10 years, then a total of 336 tons of payload would be boosted to GEO by one NEP truck over that 10-year span, this being over 5 times the payload delivered on a one-way trip in Fig. 3.

The payload fraction is also of interest (Fig. 6). If 20 tons of payload and propellant are boosted into LEO, then the net payload boosted to GEO in 100 days is about 82 percent of this 20-ton initial mass boosted to LEO.

Let's next consider the loss in power from failure of a Brayton power module and the impact of that on mission capability. Consider, for example, that we have 8 Brayton modules boosting a 16.8-ton payload in 100 days (Fig. 5). Loss of the output of one of the 8 Brayton modules would decrease power to $7 / 8$ of its rated value and thereby stretch out the time for payload delivery to $8 / 7$ of the planned time. In other words, the 16.8-ton payload would still be delivered to GEO, but in 115 days instead of 100 . The performance penalty from partial loss in power is therefore quite modest for those missions for which some power loss is contemplated and planned for.

Use of so many Brayton power modules would likely add to powerplant mass in comparison with, say, just I or 2 power modules. In general, design and development of power modules specifically for the power required on a given flight would likely produce the lowest powerplant mass, but that new development would increase program cost. The likelihood of mission success would also decline. Highest reliability could be realized through use of multiple highlydeveloped, proven power modules in combination with a mission strategy that would accept partial loss of power.

\section{Power on the Lunar Surface}

Nuclear powerplants developed and applied in these ways can also be installed on the lunar surface in order to supply power to laboratories or other installations there. Long periods of successful operation in NEP trucks shuttling between LEO and GEO (Figs. 1, 3, and 5) would assure us of the capacity for long-term operation on the lunar surface. NEP between LEO and GEO can thus increase our confidence in successful SEI missions to the lunar surface.

SP-100 with its thermoelectric converters could supply $100 \mathrm{kWe}$. In contrast with this, Brayton power modules could produce $800 \mathrm{kWe}$ from this same nuclear reactor. Use of, say, 8 Brayton modules producing $100 \mathrm{kWe}$ apiece would make those powerplants tolerant of failure as well as give program flexibility in meeting smaller demands for power such as, say, for 200 or $400 \mathrm{kWe}$.

Continued operation of these powerplants both on the lunar surface and in NEP trucks would also constitute a valuable precursor of flights of personnel to Mars. The nuclear powerplants designed for use on the lunar surface also appear suitable for use at Mars, either on the Martian surface or on its satellites; in that application, continuing operation on the lunar surface would add to our confidence in relying on them 
for use at Mars as well. On the surface of either the Moon or Mars, the refractory-metal alloys in the SP-100 reactor and its power modules require an enclosure to protect them from environmental contamination. In either case, atmospheric pressure is so low that the mass of the enclosure can be quite small, the enclosure for the Moon likely being suitable on Mars as well.

The NEP truck using the SP-100 reactor and evolved for boosting payloads from LEO to GEO (Figs. 3 and 5) would also be suitable for detailed mapping of the surfaces of the Moon and also of Mars and its satellites before selection of the landing sites. For an astronomical observatory on the Moon's far side, communication with the Earth will likely require a conmunication-relay satellite at one or more of the EarthMoon's stationary (Lagrangian) points. The same NEP spacecraft used for hauling payloads from LEO to GEO could transport that communication relay to the stationary point, power its communication receiver and transmitter, and provide the low-thrust propulsion needed for station-keeping and for attitude control. Personnel on the Martian surface will also require a comparable communication relay, and the NEP truck could similarly transport and power that relay. The nearIerm applications of an NEP truck can thus provide extensive support for various phases of the SEI missions.

In contrast with this, transportation of either cargo or personnel to Mars requires much higher powers, perhaps 10 to 20 MWe. Although we could develop a new, highperformance powerplant solely for this mission, an approach that I prefer is to identify near-Earth demands for power that will take out of such a Martian powerplant the major risks in its successful application.

\section{NEP To LLO}

NEP of cargo to the Moon has the potential to be a low-cost way to provision continuously-inhabited laboratories on the lunar surface. As we shall see, such an NEP truck can also utilize the high powers and thereby qualify the powerplants for later flights of cargo and/or personnel to Mars.

For the higher powers we will need, the current SP-100 reactor is inadequate, so we asked the SP-100 system contractor to study high-power application of the technology for the SP-100 nuclear reactor. ${ }^{10}$ In this study, conceptual designs for the nuclear heat sources were created for thermal outputs of 10 and $50 \mathrm{MWt}$. I then interpolated among the 2.5, 10, and $50-\mathrm{MWt}$ designs by assuming that mass of the nuclear heat source varies geometrically with its heat output.

As a means for increasing performance of these reactors and their associated powerplants, the body of data on the refractory-metal alloy ASTAR-8I IC (Ta-8W-1Re-0.7Hf-0.025C) attracted me. In particular, reference 11 reports the results of 98 separate long-term creep tests of this alloy over the following range of test conditions:
Temperature: 1144 to $1972 \mathrm{~K}$

Applied stress: 3.45 to $344 \mathrm{MPa}$

Duration of individual tests: 98 to $23694 \mathrm{hr}$

The total test duration for these 98 tests was $314140 \mathrm{hr}$, about 35.8 years, and duration of 6 of the individual tests exceeded $10000 \mathrm{hr}$ apiece.

If we correlate these test data in accordance with the OrrSherby-Dorn process ${ }^{12}$ and also reduce the allowed stress by iwo standard deviations of the test data from the correlating surface, then we find that this alloy will creep 1 -percent over 10 years under the following combinations of stress and temperature:

\section{(1) $1500 \mathrm{~K}$ and $28 \mathrm{MPa}$ \\ (2) $1700 \mathrm{~K}$ and $9 \mathrm{MPa}$}

Note that these conditions produce 1-percent creep, not rupture. Inasmuch as this alloy characteristically deforms about 20 percent before rupture, use of combinations of stress and temperature such as these appears entirely acceptable.

Strengths at these levels are useful in design of ducts, heat exchangers, turbine housings, and nuclear reactors, but they are inadequate for design of turbine rotors. Fortunately, the turbine rotors in these Brayton powerplants will operate at temperatures 200 to $300 \mathrm{~K}$ below turbine-inlet temperature (Ref. 9, p. 18), a feature permitting use of alloys (usually of molybdenum) not only stronger at the lower temperatures but also less dense than ASTAR-811C.

Reactor fuel pins having UN fuel and T- 111 (Ta-8W-2Hf) fuel clad have already been tested for $342000 \mathrm{hr}$; T-111 is a tantalum alloy very similar to ASTAR-81 IC although it is weaker. In these fuel-pin tests, $19000 \mathrm{hr}$ were at clad temperatures of $1600 \mathrm{~K}$ or above, and $31000 \mathrm{hr}$ were at clad temperatures of $1550 \mathrm{~K}$ or above. ${ }^{13}$ Because of the hightemperature strength of ASTAR-8IIC and because of our experience with UN fuel in T-111, I assumed that the temperature of the lithium coolant at the reactor outlet might be boosted to $1550 \mathrm{~K}$, thereby permitting Brayton-cycle operation at the turbine-inlet temperature of $1500 \mathrm{~K}$. The substantial body of materials data on UN fuel clad with $\mathrm{T}-111$ is summarized in Ref. 14.

ASTAR-1211C (Ta-12W-IRe-0.7Hf-0.025C) and ASTAR$1511 \mathrm{C}$ (Ta-15W-1Re-0.7Hf-0.025C) are tantalum alloys both newer and stronger than ASTAR-811C, but they have not been evaluated so thoroughly. Nevertheless, they offer the potential for increasing peak cycle temperature by perhaps $200 \mathrm{~K}$ above that for ASTAR-81 1C. ${ }^{15}$ Because evaluation of these stronger alloys is incomplete at this time, I will forgo the increase in operating temperature they might offer, choosing instead to limit turbine-inlet temperature to $1500 \mathrm{~K}$.

The tantalum alloys are denser than niobium alloys and hungrier for neutrons, factors increasing mass of the nuclear 
reactor but decreasing shield mass. The increase in neutroncapture cross-section can readily be compensated for by increasing fuel enrichment. But because of this alloy's higher density, mass of the reactor and shield were increased in my analysis by 10 percent over those given in Ref. 10 .

Although this change in materials gives us the capability to increase reactor-outlet temperature from 1350 to $1550 \mathrm{~K}$, we need not make this temperature change all in one step, pursuing instead the evolutionary approach previously suggested in which operating temperature would be boosted in a succession of modest steps to $1550 \mathrm{~K}$. I will spare the reader the results from such a succession of steps, leaping instead to the final, target value of $1550-\mathrm{K}$ reactor-outlet temperature and $1500-K$ turbine-inlet temperature. The reactor's heat production of $40 \mathrm{MWt}$ has been selected for the following discussion, the mass of the complete nuclear heat source then being 16 tons.

1500-K Brayton.- Given these input conditions, performance of the Brayton powerplant at $1500 \mathrm{~K}$ is that shown by Fig. 7. Minimum specific mass for the powerplant is $6.2 \mathrm{~kg} /$ $\mathrm{kWe}$. For this specific mass, $12 \mathrm{MWe}$ is generable from this $40-\mathrm{MWt}$ heat source, overall powerplant efficiency then being 0.30 .

For that Brayton powerplant, radiator area is $0.4 \mathrm{~m}^{2} / \mathrm{kWe}$, and its specific mass is $2.4 \mathrm{~kg} / \mathrm{kWe}$, mass per unit area being taken as $6 \mathrm{~kg} / \mathrm{m}^{2}$. In general, a Rankine-cycle powerplant having the same turbine-inlet temperature can reduce radiator area by about two-thirds and cut radiator mass in half. In turn, the specific mass of a competitive Rankine powerplant might be $5 \mathrm{~kg} / \mathrm{kWe}$ instead of Brayton's 6.2. On the other hand, boosting turbine-inlet temperature of the Brayton powerplant from 1500 to $1700 \mathrm{~K}$ through use of either ASTAR-121 IC or ASTAR-15IIC (as above) would also decrease its specific mass to $5 \mathrm{~kg} / \mathrm{kWe}$.

Compare Figs. 4 and 7; specific mass of the reactorBrayton powerplant has been cut in half. The two large contributors to this reduction are the following: Designing the nuclear heat source for higher heat production markedly cut its specific mass; increasing the reactor's heat output by a multiplicative factor of 16 raised mass of the nuclear heat source by a factor of only 5 . At the higher cycle temperature ( $1500 \mathrm{~K}$ instead of 1300 ), radiator area and mass per kilowatt have been cut in half.

Payload Delivery to LLO.- Now let's explore use of the 12-MWe Brayton powerplant at $1500 \mathrm{~K}$ and having specific mass of $6.2 \mathrm{~kg} / \mathrm{kWe}$ (Fig. 7) for NEP to LLO. Once again, the NEP truck for this mission could make one-way or roundtrips. For simplicity, I will consider only the roundtrips. For the resupply mass in LEO, I assumed that a new launch vehicle would place 150 tons into a circular orbit at an altitude of $1000 \mathrm{~km}$; all of my results are based on this 150-ton resupply niass. And, as before, $2 \mathrm{~kg} / \mathrm{kWe}$ was allocated for power conditioning and the electric thrusters, total specific mass for the complete propulsion system then being $8.2 \mathrm{~kg} / \mathrm{kWe}$. Exploration of a range of possible design points for this NEP truck showed that $12 \mathrm{MWe}$ of electric power was appropriate to the resupply mass of 150 tons, that power level being the focus of the discussion concerning Fig. 7.

For roundtrips, this resupply mass would consist of the payload to be delivered to LLO plus the propellant required by the NEP truck in order to make the roundtrip. In turn, the relation between the payload delivered and the Earth-Moon transit time is shown by Fig. 8. For the transit time of 100 days, 125 tons of payload can be placed in LLO (payload mass fraction of 0.83 ), the power required being the $12 \mathrm{MWe}$ that is the focus of the discussion of Fig. 7. Add to this the 42 days for return to LEO, and roundtrip time is 142 days, a time fitting comfortably within a 6 -month resupply period. Alternatively, a 100-ton payload could be delivered to LLO in 50 days, the power required then being $11 \mathrm{MWe}$. For the same $40-\mathrm{MWt}$ nuclear heat source, a Brayton power system can generate this $11 \mathrm{MWe}$ at the same specific mass as for $12 \mathrm{MWe}$ (Fig. 7). For this class of NEP truck, very large payloads can thus be placed in LLO in time periods perfectly acceptable for transportation of cargo.

For transit times ranging from 50 to 200 days, optimum specific impulse varies from 4800 to $22000 \mathrm{sec}$, extending beyond the range of experience even with ion thrusters. Throughout this range, ion thrusters have substantial advantages over MPD thrusters, not only in both efficiency and thrust but also in state of technology.

Let's next consider the consequence of partial failure of the propulsion system. For specificity, consider the 12-MWe Brayton power-generating system in Fig. 7 propelling 125 tons of payload to LLO in 100 days (Fig. 8); further consider that this 12-MWe powerplant contains 6 power-generating modules of $2 \mathrm{MWe}$ each. Failure of one of these modules would still leave us with $10 \mathrm{MWe}$ to do the transportation job. The failure would be most serious if the NEP truck had just begun its transit from LEO to LLO. At this reduced power, the transit to LLO would then require 120 days instead of 100 , a delay tolerable for cargo. (With $5 / 6$ the rated power, $6 / 5$ the transit time is needed.) The essential point is that the same payload would still be delivered to the same final destination, albeit in a somewhat longer period. If this partial failure occurred at an altitude higher than LEO, the time delay would be smaller than the 20 days cited here. With appropriate design of the powerplant and with suitable mission plans, mission execution is then very tolerant of partial failure of the powerplant.

\section{Preparing for Missions to Mars}

Before actually sending people to Mars, we need to gain confidence in all of the means required for doing just that. Even in the near term, we can begin programs that, although use ful in their own rights, will give us the requisite confidence to launch on such a mission.

Extremely valuable precursors of missions to explore Mars, both inhabited and uninhabited, would be applications of 
nuclear power and NEP for boosting payloads to GEO and then during the lunar missions, whether on the lunar surface itself or for transporting very large payloads to LLO. A crucial factor in this suggested program plan is the manner in which such a venturesome future could be built on a successful past. At each stage of the program, knowledge and experience gained from a succession of program steps, each of low cost and low risk, will give us confidence in the success of each succeeding step. This confidence of success is broader than simply confidence of successfully completing a given mission, but also includes our abilities to plan programs whose costs, schedules, and performance are predictable. Consider, for example, the following successive program steps.

Through direct use of the current SP-100 reactor with its outpul of $2.5 \mathrm{MWt}$, Brayton power generation can produce $800 \mathrm{kWe}$. Use of power modules of, say, $100 \mathrm{kWe}$ apiece would permit ready adaptation of the powerplant to various demands for power, eclipsing thermoelectric power generation. Our confidence in the SP- 100 reactor program can also be increased by adding a $150-\mathrm{K}$ margin in reactor operating temperature; even at this reduced operating temperature, Brayton powerplant specific mass of $17 \mathrm{~kg} / \mathrm{kWe}$ is achievable (Fig. 2). Evolution of the reactor to its design operating temperature of $1350 \mathrm{~K}$ would reduce specific mass of the Brayton powerplant to $13 \mathrm{~kg} / \mathrm{kWe}$ (Fig. 4), about one-fourth the specific mass predicted for the thermoelectric powerplant. This powerplant, whether at its original or evolved turbineinlet temperature, would be extremely valuable in boosting payloads to GEO, initially on one-way and later on roundtrips between LEO and GEO. That same NEP truck could also transport observation equipment to the Moon and to Mars for detailed mapping of their surfaces, thereby making early contributions to the SEI program. In support of the program on space science, NEP exploiting this powerplant would also enable difficult missions to the outer planets (Neptune, for example), to comet rendezvous, and out of the ecliptic plane.

A high-power version of that same powerplant could provide 10 to $25 \mathrm{MWe}$ of electric power. (The feasibility of these power levels in space is evident in terrestrial applications of Brayton-cycle gas turbines, which routinely generate 10 to $200 \mathrm{MWe}$ of power in central power stations.) Inasmuch as the best power levels for missions to the Moon and to Mars will not be accurately known until we are closer to actual mission execution, the powerplant itself could be modular in its construction so as to provide for ready adaptation to specific mission needs. This modularity would also give to the powerplant a resilience making its performance tolerant of failure and contributing to both successful completion of the mission and to survival of the flight personnel.

These high-performance powerplants could provide these high powers either in space or on the surface of celestial bodies. Exploitation of these powerplants in an NEP space truck would also permit transportation of very large and massive payloads either to low lunar orbit or to orbit about Mars, both one-way and roundtrips being feasible. At present, that same concept must also be viewed as competitive for travel of people to orbit about Mars and return.

Reactor-Brayton power generation has thus the capacity to generate a wide range of powers extending from 100 s of kilowatts with the current SP- 100 reactor to 10 s of MWe with redesigned, growth versions of this reactor. Progressive evolution of that single concept in a diversity of applications can give us the confidence we need in order to advocate and to carry out the SEI missions. In contrast with this potential, thermoelectric power generation is a virtual dead end because it is limited to only the very smallest powers ( $100 \mathrm{kWe}$ or so).

Exploitation of Space Station to Demonstrate Enabling Technology for SEI. One might ask how this Brayton technology might be both explored and exploited aboard the Space Station. Another expression of the same thought is the following: How could we not only generate useful power aboard the Space Station Freedom but also investigate advanced power generation in order to gain confidence in even the very first application of SP-100 and, in particular, to decrease the risks in the SEI program?

The solar-Brayton concept selected for the growth version of the Space Station would use the latent heat of fusion of the mixed salt LiF-CaF ${ }_{2}$ for storing heat for use during the time of solar occultation. With its melting point of $1042 \mathrm{~K}$, this heat store can sustain a turbine-inlet temperature of about $1000 \mathrm{~K}$, a value too low for effective use of the SP-100 reactor.

Let's contemplate how the solar-Brayton powerplant for the Space Station might be redirected in order to diminish the risks in the SEI power program, the solar-Brayton powerplant being exploited as a precursor of a reactor-Brayton powerplant specifically in order to decrease the risks in SEI's nuclear-power program. First, use molten lithium as the heatstorage medium for the solar powerplant. Not only is lithium the reactor coolant for SP-100 but when used in combination with a solar-Brayton powerplant, its sensible-heat content is more than twice the latent heat of the $\mathrm{LiF}-\mathrm{CaF}_{2}$ eutectic. ${ }^{16}$ Second, build the hot portion of the Brayton powerplant of refractory-metal alloy, partly for compatibility with the molten lithium, partly for adequate strength at high temperatures, and, finally, for suitability for conversion from solarpower generation to nuclear-power generation with the SP-100 reactor.

Evolution of solar-dynamic power generation in this way is a substantial technological challenge in its own right, and the magnitude of that challenge should not be minimized. But two key factors are crucial in such a program. (1) The risks inherent in solar-power generation are much more tolerable than those from any nuclear powerplant. And (2) the Space Station Freedom is the best place in space to eliminate the risks associated with an entirely new class of power generator.

The Space Station, by its nature, provides an environment that is risk-tolerant, and SEI should exploit that. In part, this tolerance of risk stems from the modular construction of the power system aboard the Station. If an advanced powerplant were to fail aboard the Station, operation of the Station could 
continue with power from its solar arrays. Next, because of the repeated visits planned for the Space Station, we could conceivably repair or replace the failed power module. In this low-risk way, we could evolve and demonstrate an advanced concept for solar-power generation aboard the Station and thereby eliminate considerable risk from the SEI nuclearpower program.

In adapting such a solar powerplant for use with the SP-100 reactor, an absolutely crucial factor is that the SP- 100 nuclear reactor uses a pumped stream of molten lithium to transport its heat to the power-generating system. Successful development of a solar-Brayton powerplant using molten lithium as its heat supply would take much of the technological risk out of coupling such a Brayton powerplant to the nuclear reactor; if molten lithium were supplied at the same temperature and flow rate, the Brayton powerplant would scarcely be aware that the nature of its heat source had changed from solar to nuclear.

An additional factor is the manner in which such a solar powerplant could evolve, a programmatic approach both reducing program risk and improving performance. Although use of a fusible salt is tied to its melting point, the molten lithium and the Brayton cycle can both operate very effectively over a wide range of peak temperatures. For this very reason, an evolutionary power program could be constructed with the following basic elements: (1) Use of the refractorymetal alloy ASTAR-81IC and molten lithium as the heat supply would permit powerplant design for operation at turbine-inlet temperatures up to $1500 \mathrm{~K}$. (2) The powerplant could initially be operated at turbine-inlet temperature of perhaps $1200 \mathrm{~K}$, the $300-\mathrm{K}$ reduction being pure margin. (3) Following successful operation at this low temperature, the peak cycle temperature could be raised in a succession of modest increments progressing toward the design value of $1500 \mathrm{~K}$. (4) That concept for a Brayton powerplant, operated initially with solar energy as its heat source, could be readily switched to a nuclear-energy source after we become fully confident of its success with solar energy. Use of such a solar powerplant aboard the Space Station could thereby markedly reduce the risks in use of nuclear power in the SEI missions to the Moon and to Mars.

When we contemplate these extended missions to the Moon and to Mars, how we might plan and execute them with confidence and how we might protect the personnel involved, we ought also to ask how the Space Station can provide the answers we seek. To a substantial degree, the program for the Space Station should be reshaped not only to provide some of these answers but also in order to diminish the risks to which the participating personnel will be subjected during the missions to the Moon and to Mars.

\section{CONCLUDING REMARKS}

(1) As NASA contemplates sending personnel on longterm missions to the Moon and to Mars, we technologists and mission planners are responsible for delineating the costs and risks involved and for formulating program plans that will reduce these costs and risks. In our striving to reduce costs and risks, a crucial aspect of those plans is program continuity, that is, continuing application of a given technology over a long period so that experience will accumulate from extended testing here on Earth and from a diversity of applications in space.

(2) Nuclear power differs in kind from chemical and solar power generators in space, not just in degree. Its distinctive features include life of 10 years or more, compactness, and, most important, the capacity to produce power in either sunlight or darkness. The concern for nuclear safety must, of course, aiso be encompassed by the program.

(3) Because of the long durations of space missions for which nuclear power is contemplated, development of nuclear power takes a long time (10 years or more). The most trustworthy demonstration of long-term performance and endurance of a given powerplant concept would be through its actual utilization in space. For these reasons, there is great value in a programmatic approach to nuclear power that utilizes a single concept for power generation in widespread applications.

(4) In general, design of a powerplant for its first application should include considerable design margin, an approach not only decreasing the time for development of the powerplant but also diminishing the cost and risk in its initial development and application. That approach would also permit later evolution of the powerplant concept in a succession of modest steps, each of low cost and low risk and with future gains building on past successes. In this evolutionary approach, the powerplant would evolve to its ultimate potential without any sacrifice in the performance to be ultimately achieved.

(5) A lithium-cooled nuclear reactor, such as SP-100's, has the characteristics we seek. Not only is the reactor compact but it is suitable for use with a diversity of powergenerating systems. Among these power generators, the Brayton cycle, with its high efficiency and long life already demonstrated, can produce the most power from a given nuclear heat source and can thereby extend its range of application and increase its value. Inasmuch as the Brayton's working gas is not tied to a given boiling temperature, the Brayton powerplant can be operated over a considerable range of turbine-inlet temperature, a feature making it suitable for the incremental, evolutionary approach I propose.

(6) From the $2500-\mathrm{kWt}$ SP-100 nuclear reactor currently planned, the Brayton-cycle powerplant concept can generate 700 or $800 \mathrm{kWe}$ rather than the $100 \mathrm{kWe}$ from thermoelectric power generation, can reduce powerplant specific mass by a factor of 3 , and can simultaneously introduce a $150-\mathrm{K}$ design margin for the nuclear reactor. In its application to NEP, this Brayton powerplant can boost 39-ton payloads from LEO to GEO in 100 days, far beyond what thermoelectric power generation can achieve. In contrast, thermoelectric generation is dead-ended in its range of power output. 
(7) Now consider extension of this reactor-Brayton concept to higher temperatures $(1500 \mathrm{~K})$ and power levels ( $12 \mathrm{MWe})$ and its application as an NEP truck hauling cargo from LEO to LLO. From 150 tons boosted to LEO, that NEP truck could deliver 125-ton payloads to LLO in 100 days, the spacecraft itself making repeated round trips.

(8) That same 12-MWe powerplant and its ion thrusters are a promising candidate for exploration of Mars, for transportation of cargo from LEO to orbit about Mars, and for return of materials from Mars to Earth. The same concept also merits further study for transportation of personnel to Mars and return.

(9) The earliest, enabling application of this Brayton-cycle technology at the power level of about $100 \mathrm{kWe}$ appears to be as a solar-dynamic powerplant aboard the Space Station. Such a solar-dynamic powerplant could utilize refractorymetal alloys for its hottest portions and exploit the very large sensible heat of molten lithium for its heat storage, eliminating the fusible salt currently planned along with its phase change, volume change, fixed melting point, and low heat of fusion. Not only would that programmatic approach improve performance of the solar-dynamic powerplant but also margin would be added to the program along with the capacity to evolve the powerplant to vastly improved performance at turbine-inlet temperatures up to $1500 \mathrm{~K}$.

(10) Now consider application of that same solar-Brayton powerplant with nuclear energy. If a stream of molten lithium heated by a nuclear reactor were substituted for the supply of molten lithium heated by the Sun, the Brayton power generator would scarcely be aware of the change. In this way, successful operation of the solar-powered precursor of nuclear power would markedly reduce the programmatic risks in applying nuclear power in space.

(II) Brayton-cycle power generation is the key to these programmatic benefits. Its high demonstrated efficiency makes it not only suitable but valuable for solar-power generation aboard the Space Station. Operation of such a precursor solar powerplant aboard the Space Station would diminish the risks in generating power from the SP- 100 reactor, and its high efficiency would raise by a factor of 7 or 8 the power producible from that reactor as well as the payload mass boostable from LEO to GEO. Daily operation of Brayton-cycle gas turbines producing $10 \mathrm{~s}$ to $100 \mathrm{~s}$ of $\mathrm{MWe}$ here on Earth also give firm evidence of the feasibility of Brayton powerplants to generate 10 or more MWe for electric propulsion to LLO and to Mars.

(12) This wide application of a single technology (for solar power as well as nuclear power, and for power outputs ranging from $100 \mathrm{kWe}$ to $10 \mathrm{~s}$ of $\mathrm{MWe}$ ) has the potential for great reductions in the costs and the risks of venturesome new programs such as the contemplated SEI missions to the Moon and to Mars.

(13) We need to form an integrated view of the missions SEI will carry out, near-term as well as far. And we need to form a view of the ways in which these programs can mutually support one another. Near-term programs should be reshaped in order to provide for the long-term missions the demonstrations and the enabling technologies they need. This means, for example, that we should direct and fund the Space Station to develop and demonstrate the solar-Brayton powerplant that will be useful as the power generator for use with the SP- 100 nuclear reactor. Missions in Earth orbit should evolve and demonstrate the technologies crucial to long-term missions on the lunar surface. And the program for the lunar laboratories should evolve and demonstrate the enabling technologies for exploration of the surface of Mars and for flights of human beings to Mars and return.

(14) In add ition to the judgments above that concern power generation, we might also seek to form a judgment concerning electric propulsion. Consider the optimum specific impulses for the following missions selected from Figs. 3, 5, and 8.

\begin{tabular}{|c|c|c|c|c|c|}
\hline $\begin{array}{c}\text { Peak } \\
\text { temper- } \\
\text { ature, } \\
\mathrm{K}\end{array}$ & $\begin{array}{c}\text { Power, } \\
\mathrm{kW}\end{array}$ & Trip & $\begin{array}{c}\text { Transit } \\
\text { time, } \\
\text { day }\end{array}$ & $\begin{array}{c}\text { Payload, } \\
\text { ton }\end{array}$ & $\begin{array}{c}\text { Specific } \\
\text { impulse, } \\
\mathrm{sec}\end{array}$ \\
\hline 1150 & 700 & $\begin{array}{c}\text { 1-way } \\
\text { to GEO }\end{array}$ & 100 & 39 & 2700 \\
1300 & 850 & $\begin{array}{c}\text { RT } \\
\text { to GEO } \\
\text { RT } \\
\text { to LLO }\end{array}$ & 100 & 125 & 10500 \\
\hline
\end{tabular}

Nomenclature:

GEO geosynchronous Earth orbit

LEO low Earth orbit

RT round trip

LLO low lunar orbit

Although we might debate selection of either ion or magnetoplasmadynamic (MPD) thrusters for the earliest mission listed, the selection for the more attractive missions is clear: For the range of specific impulse that these missions require ( $5000 \mathrm{~s}$ and above), MPD thrusters are simply not competitive in efficiency and thrust with ion thrusters.

If, as herein proposed for power generation, we emphasize and pursue, even for the earliest missions, the thruster concept having the greatest benefit to the SEI missions, then we should exploit the ion thrusters for all three of these applications. In that way, we could gain for the thrusters the same confidence in their performance and durability as we would for the power generating systems.

\section{References}

1. Harper, A., "Study of Reactor Brayton Power Systems for Nuclear Electric Spacecraft," AiResearch Mfg. Co., AIRESEARCH-31-3321, 1979 (also, NASA CR-168942). 
2. Mason, L.S., Bloomfield, H.S., and Hainley, D.C., "SP100 Power System Conceptual Design for Lunar Base Applications," Sixth Symposium on Space Nuclear Power Systems, Institute for Space Nuclear Power Studies, University of New Mexico, Albuquerque, NM, 1989, pp. 9-12. (Also, NASA TM-102090).

3. Heller, J.A., Moss, T.A., and Barna, G.J., "Study of a 300Kilowatt Rankine-Cycle Advanced Nuclear-Electric Space-Power System," NASA TM X-1919, 1969.

4. Bankston, C.P., "Alkali Metal Thermoelectric Conversion (AMTEC) Technology Status Review," Space Nuclear Power Systems 1986, Orbit Book Co., Inc., Malabar, FL, 1987, pp. 199-207.

5. Samuelson, S.L., and Dahlberg, R.C., "Thermionic Fuel Element Verification Program -- Summary of Results," Seventh Symposium on Space Nuclear Power Systems, Institute for Space Nuclear Power Studies, University of New Mexico, Albuquerque, NM, 1990, pp. 77-84.

6. "SP-100 Reference Flight System, System Design Review," vol. I, General Electric Company, Valley Forge, PA, May 1988, p. 1.8-27.

7. "Annual Technical Review," SP-100 Ground Engineering System Project, General Electric Company, Valley Forge, PA, Jan. 23, 1991.

8. Pawlik, E.V., and Phillips, W.M., "A Nuclear Electric Propulsion Velicle for Planetary Exploration," J. Spacecraft and Rockets, vol. 14, no. 9, Sept. 1977, pp. 518-525.

9. English, R.E., "Power Generation from Nuclear Reactors in Aerospace Applications," NASA TM-83342, 1982.

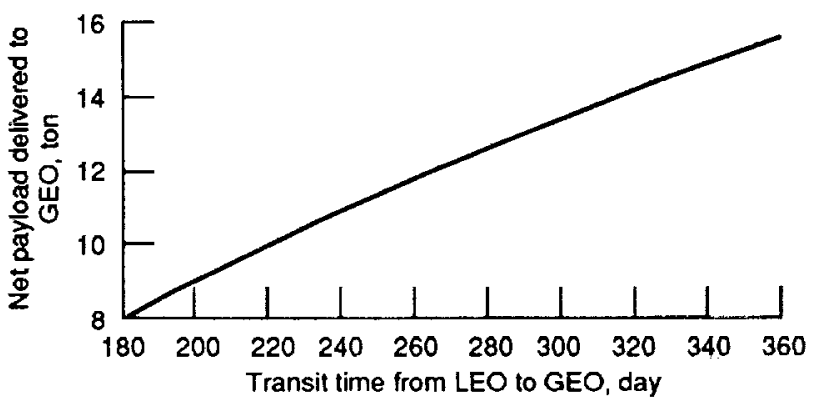

Figure 1.-One-way to GEO via the SP-100 power plant. $1300 \mathrm{~K}$; reactor + shield $=3049 \mathrm{~kg}$.
10. Smith, M., and Stewart, S., "SP-I00 Reactor Scalability Study," General Electric Co., 1989.

11. Klopp, W.D., Titran, R.H., and Sheffler, K.D., "LongTerm Creep Behavior of the Tantalum Alloy Astar811 ," NASA TP 1691, 1980.

12. Orr, R.L., Sherby, O.D., and Dorn, J.E., "Correlations of Rupture Data for Metals at Elevated Temperatures," Trans. ASM, vol. 46, 1954, pp. 113-128.

13. Mayer, J.T., Smith, R.L., Weinstein, M.B., and Davison, H.W., "EXFILE: A Program for Compiling Irradiation Data on UN and UC Fuel Pins," NASA TM X-68226, 1973.

14. Gluyas, R.E. and Watson, G.K., "Materials Technology for an Advanced Space Power Nuclear Reactor Concept -- Program Summary," NASA TN D-7909, 1975.

15. Buckman, R.W., Jr., and Ammon, R.L., "Comparative Strength Properties of Tantalum Alloys ASTAR-8IIC, ASTAR-1211C, and ASTAR-15] IC," Seventh Symposium on Space Nuclear Power Systems, Institute for Space Nuclear Power Studies, University of New Mexico, Albuquerque, NM, 1990, pp. 154-157.

16. English, R.E., "Speculations on Future Opportunities to Evolve Brayton Powerplants Aboard the Space Station," Space Nuclear Power Systems 1987, M.S. El-Genk and M.D. Hoover, eds., Orbit Book Co., Inc., Malabar, Fl, 1987, pp. 41-52 (also, NASA TM-89863).

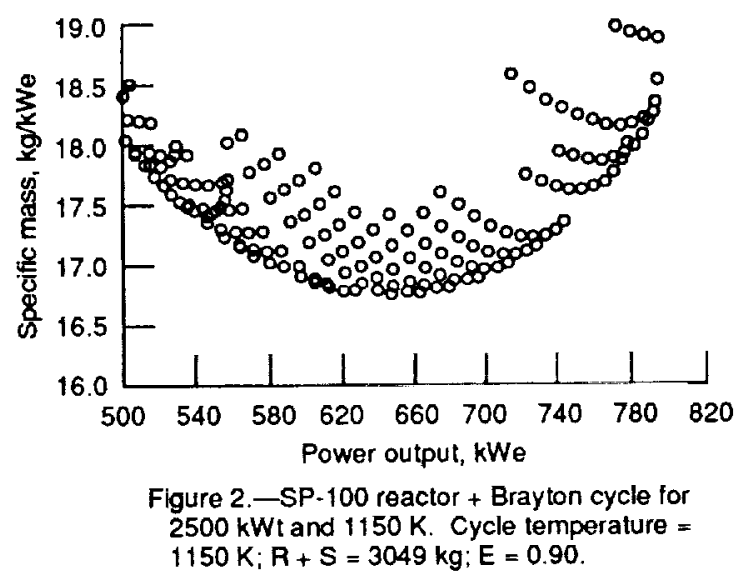




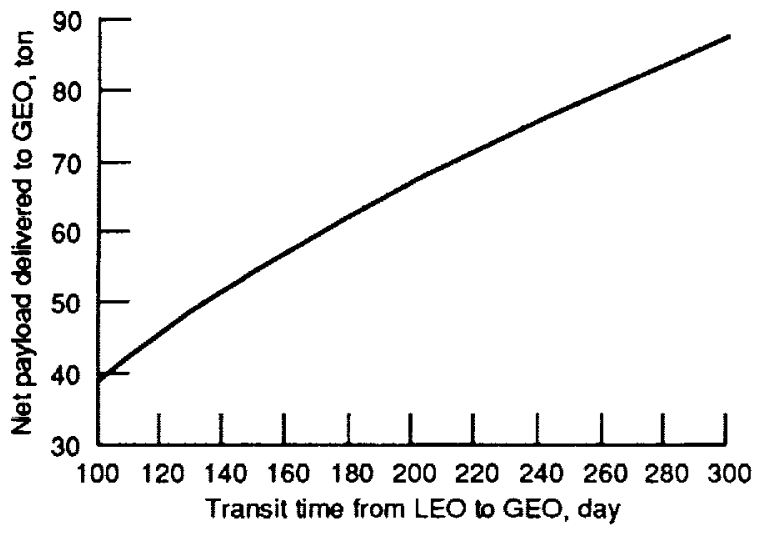

Figure 3.-One-way to GEO via the SP-100 reactor + Brayton power generation. $1150 \mathrm{~K}$; reactor + shield = $3049 \mathrm{~kg}$

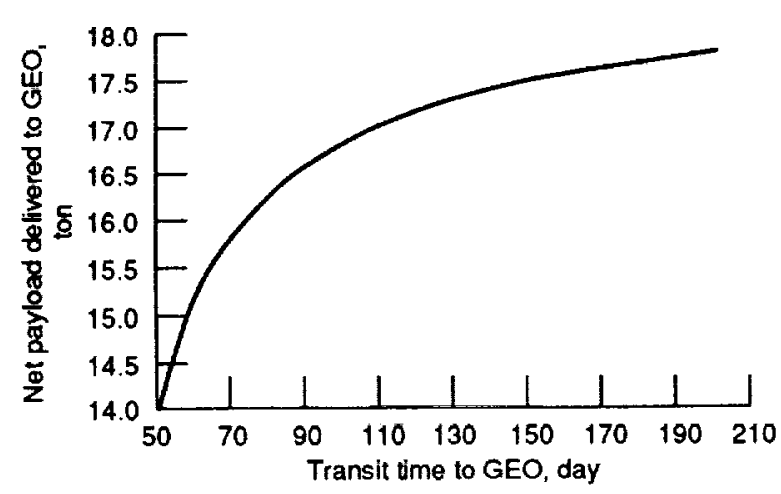

Figure 5.-Optimum roundtrips, LEO to GEO. Powerplant: $850 \mathrm{kWe}$ at $15.6 \mathrm{~kg} / \mathrm{kWe}$.

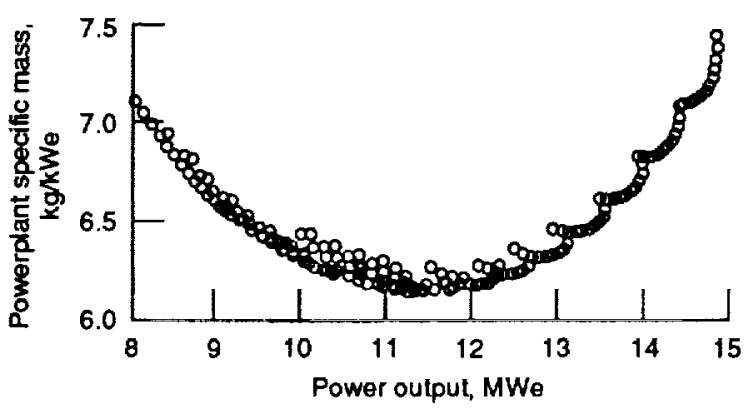

Figure 7.-Brayton power generation plus 40-MWt $S P-100$ reactor. Temperature $=1500 \mathrm{~K} ; R+S=$ 16 tons: $E=.85$.

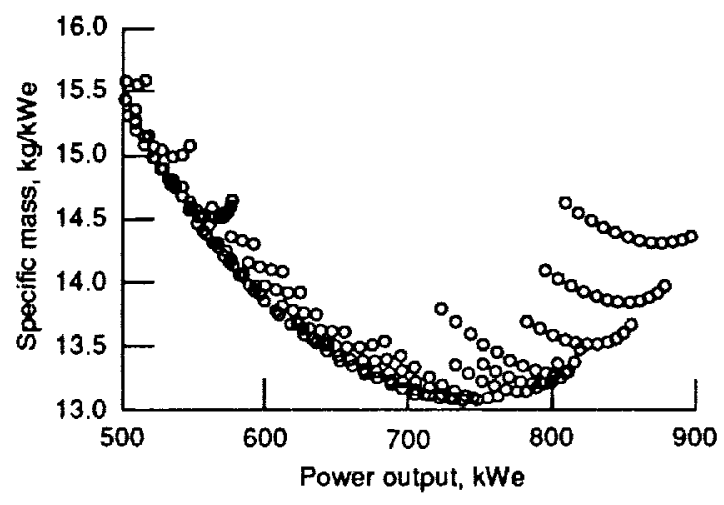

Figure 4.-SP-100 reactor + Brayton cycle for $2500 \mathrm{kWt}$ and $1300 \mathrm{~K}$. Cycle temperature $1300 \mathrm{~K} ; \mathrm{R}+\mathrm{S}=3049 \mathrm{~kg} ; \mathrm{E}=0.92$.

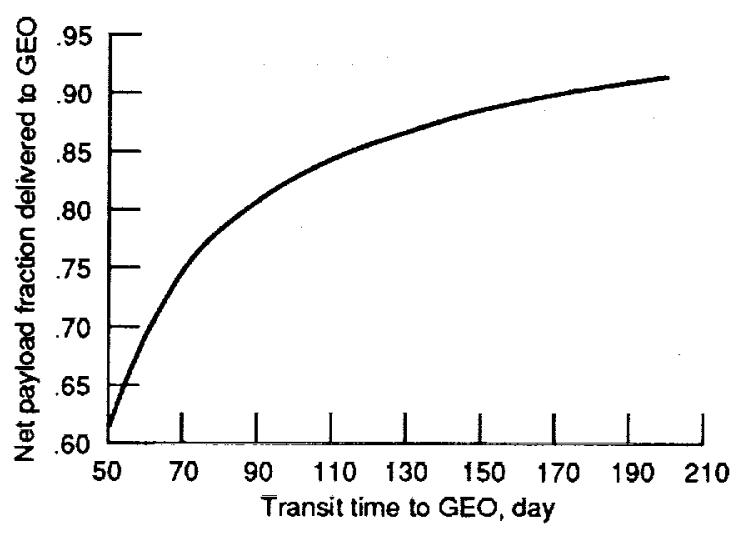

Figure 6.-Optimum roundtrips, LEO to GEO. Powerplant: $850 \mathrm{kWe}$ at $15.6 \mathrm{~kg} / \mathrm{kWe}$.

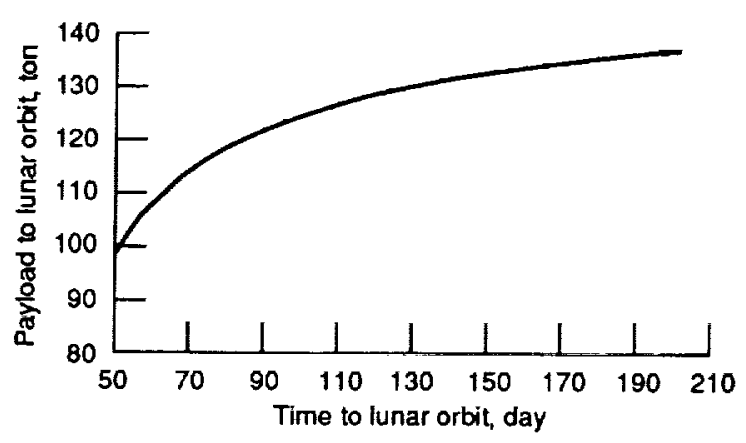

Figure 8.-Optimum lunar roundtrips, LEO to LLO. Resupply mass in LEO, 150 tons. 


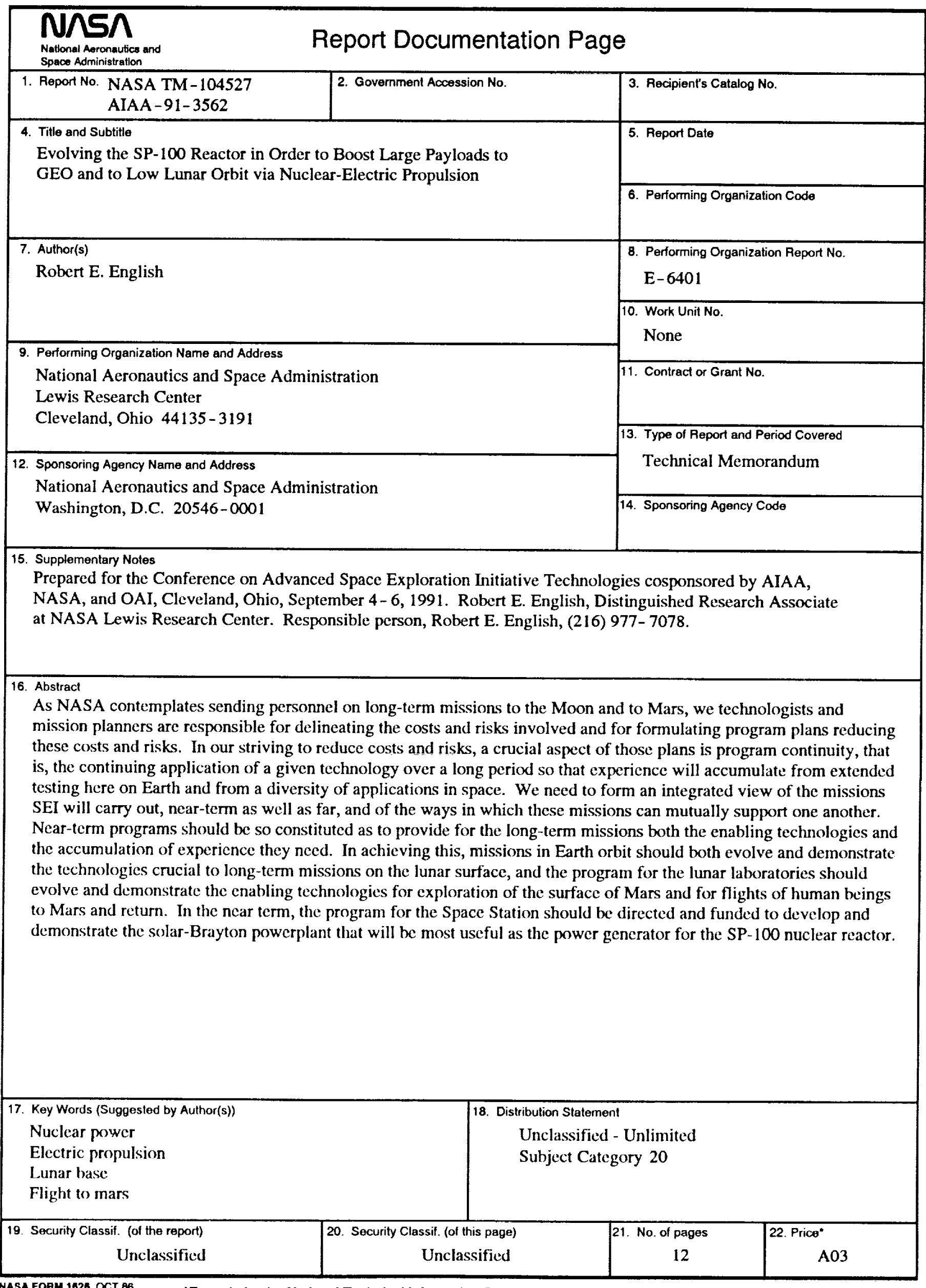

